\title{
Challenges to primary care in diagnosing and managing depression in children and young people
}

\author{
Tami Kramer consultant child and adolescent psychiatrist ${ }^{1}$, Lorraine Als research psychologist ${ }^{2}, \mathrm{M}$ \\ Elena Garralda emeritus professor ${ }^{2}$
}

${ }^{1}$ Westminster Child and Adolescent Mental Health Services, London NW8 OPJ, UK; ${ }^{2}$ Imperial College London, Centre for Mental Health, Hammersmith Hospital Campus, Imperial College London, London, UK

The National Institute for Health and Care Excellence (NICE) guideline summary recommended that Child and Adolescent Mental Health Services should work with primary healthcare professionals to develop systems for detecting, assessing, supporting, and referring depressed children and young people, with provision for those who are less seriously affected within primary care. ${ }^{1}$ This recommendation does not take into account the challenges to primary care services in fulfilling this role.

A survey of UK GPs found that many GPs feel ill equipped to deal with young people's emotional distress and lack clarity about managing psychological difficulties. ${ }^{2}$ Education and training in discriminating between emotional distress and clinical depression in young people, coupled with management techniques appropriate for primary care, are needed to facilitate compliance with NICE guidance.

We have reported on the development and evaluation of a programme (TIDY: therapeutic identification of depression in young people) that trains primary care practitioners (PCPs), GPs, and primary care nurses to differentiate between emotional turmoil and depression, and to implement setting appropriate management techniques. Our research has shown that it is feasible to train PCPs in the implementation of this programme, and that the programme is acceptable to PCPs and young people and can potentially reduce associated functional impairment. ${ }^{3}$ Nevertheless, this work has also identified concerns among PCPs about managing emotional distress in young people, ${ }^{4}$ including the unnecessary medicalisation of distress and the burden of broadening the PCP role.

Although evidence exists from the US, ${ }^{5}$ demonstration of efficacy in the UK is required before PCPs engage in this work more fully. Investment in relevant research is needed before NICE guidelines can be implemented and the opportunity for intervention for young people can be realised.

Competing interests: TK and MEG have been involved in the development and evaluation of the TIDY programme (therapeutic identification of depression in young people).

Full response at: www.bmj.com/content/350/bmj.h824/rr.

1 Hopkins K, Crosland P, Elliott N, et al; on behalf of the Clinical Guidelines Update Committee $\mathrm{B}$. Diagnosis and management of depression in children and young people. BMJ 2015;350:h824. (4 March.)

2 Roberts $\mathrm{JH}$, Crosland A, Fulton J. "I think this is maybe our Achilles heel ..." exploring GPs' responses to young people presenting with emotional distress in general practice: a qualitative study. BMJ Open 2013;3:e002927.

3 Kramer T, lliffe S, Bye A, et al. Testing the feasibility of therapeutic identification of depression in young people in British general practice. J Adolesc Health 2012;52:539-45. lliffe S, Gallant C, Kramer T, et al. Therapeutic identification of depression in young people: lessons from the introduction of a new technique in general practice. $\mathrm{Br} J$ Gen Pract 2012;62:e174-82.

5 Kramer T, Garralda ME. Assessment and treatment in non-specialist community health care settings. In: Thapar A, Pine D, Leckman J, et al, eds. Rutter's child and adolescent psychiatry. 6th ed. Wiley [forthcoming].

Cite this as: $B M J$ 2015;350:h2512

๑) BMJ Publishing Group Ltd 2015 